peaks was confirmed, in each case, for five randomly selected samples which were analyzed by GC-MS. Although there is no linear, quantitative correlation between the amounts of 3-hydroxyisovaleric acid and isovaleryl glucuronide, it is apparent that isovaleryl glucuronide is more likely to be excreted when the amount of 3-hydroxyisovaleric acid is high. For example, as can be seen in Table 1, when the amount of 3-hydroxyisovaleric acid was greater than $0.26 \mathrm{mg} / \mathrm{mg}$ creatinine, isovaleryl glucuronide was present in seven out of eight samples. When the amount of 3-hydroxyisovaleric acid was equal to or less than $0.26 \mathrm{mg} / \mathrm{mg}$ creatinine, isovaleryl glucuronide was present in only 23 of 64 samples. Table 2 shows that the average amount of 3-hydroxyisovaleric acid was more than five times greater in those samples that contained isovaleryl glucuronide, whereas the amount of isovalerylglycine was roughly equal in both groups. The data therefore does indicate that glucuronide conjugation of isovaleric acid is more prevalent when the glycine conjugation system is saturated. It should be noted, however, that of the 49 samples which contained no measurable amount of 3-hydroxyisovaleric acid, 18 contained isovaleryl glucuronide in varying amounts ranging up to $0.54 \mathrm{mg} / \mathrm{mg}$ creatinine (see Table 1). There may be other factors involved in the stimulation of the glucuronide detoxification mechanism. Nevertheless, glucuronide conjugation appears to be assuming the role of a secondary, yet important, detoxification mechanism in isovaleric acidemia.

\section{REFERENCES AND NOTES}

1. Budd, M. A., Tanaka, K., Holmes, L. B., Efron, M. L., Crawford, J. D., and Isselbacher, K. J.: Isovaleric aciemia: clinical features of a new genetic defect of leucine metabolism. N. Engl. J. Med., 277 (1976).

2. Dutton, G. J.: Glucuronic Acid, Free and Combined. (Academic Press, New York, 1966).

3. Fenselau, C. and Johnson, L.: Analysis of intact glucuronides by mass-spec- trometry and gas chromatography-mass spectrometry. Drug Metab. Dispos., 8: 274 (1980).

4. Lehnert, W.: 3-Hydroxyisoheptanoic acid: a new metabolite in isovaleric acidemia. Clin. Chim. Acta, 113: 101 (1981)

5. Lehnert, W.: Excretion of $\mathrm{N}$-isovalerylglutamic acid in isovaleric acidemia. Clin. Chim. Acta, 116: 249 (1981)

6. Mrochek, J. E. and Rainey, W. T.: Gas chromatography and mass spectrometry of some trimethylsilyl derivatives of glucuronide. Anal. Biochem., 57: 173 (1974).

7. Rhead, W. R. and Tanaka, K. Demonstration of a specific mitochondrial isovaleryl CoA dehydrogenase deficiency in fibroblasts from patients with isovaleric acidemia. Proc. Natl. Acad. Sci. U.S.A., 77: 580 (1980).

8. Tanaka, K., Budd, M. A., Efron, M. L., and Isselbacher, K. J.: Isovaleric acidemia: a new genetic defect of leucine metabolism. Proc. Natl. Acad. Sci. U.S.A., 56: 236 (1966).

9. Tanaka, K. and Isselbacher, K. J.: The isolation and identification of Nisovalerylglycine from urine of patients with isovaleric acidemia. J. Biol. Chem., 242: 2966 (1967).

10. Tanaka, K., Orr, J. C., and Isselbacher, K. J.: Identification of 3-hydroxyisovaleric acid in the urine of a patient with isovaleric acidemia. Biochem. Biophys. Acta, 152: 638 (1968).

11. Tanaka, K. and Rosenberg, L. E.: Disorders of branched chain amino acid and organic acid metabolism. In: J. B. Stanbury, J. B. Wyngaarden, D. S. Fredrickson, J. L. Goldstein, and M. S. Brown: The Metabolic Basis of Inherited Disease. (McGraw-Hill, New York, 1982).

12. Tanaka, K., West-Dull, A., Hine, D. G., Lynn, T. B., and Lowe, T.: Gas chromatographic method of analysis for urinary organic acids. II. Description of the procedure, and its application to diagnosis of patients with organic acidemia's. Clin. Chem. 26:1847 (1980).

13. Truscott, R. J. W., Malegan, D., McCairs, E., Burke, D., Hick, L., Sims, P. Halpern, B., Tanaka, K., Sweetman, L., Nyhan, W. L., Hammond, J., Bumack, C., Haan, E. A., and Danks, D. M.: New metabolites in isovaleric acidemia. Clin. Chim. Acta, 110:187 (1981).

14. Requests for reprints should be addressed to: Kay Tanaka, M.D., Yale University School of Medicine, Department of Human Genetics, 333 Cedar Street, P.O. Box 3333, New Haven, Connecticut, 06510, (USA).

15. We would like to thank Ms. Kelly Beckman for her assistance in the preparation of this manuscript.

16. Received for publication April 19, 1983.

17. Accepted for publication August 10, 1983.

\title{
Colostrum-Induced Enteric Mucosal Growth in Beagle Puppies
}

\author{
WILLIAM C. HEIRD, ${ }^{(27)}$ STEVEN M. SCHWARZ, AND INGE H. HANSEN \\ Department of Pediatrics and Institute of Human Nutrition, Columbia University College of Physicians and \\ Surgeons, New York, New York, USA
}

\section{Summary}

To evaluate the role of artificial feeding and natural feeding in early growth of enteric mucosa, we determined enteric mucosal mass, protein and DNA content, and disaccharidase activities in beagle puppies at birth, and after $24 \mathrm{~h}$ of either natural or artificial feeding. Despite similar increases in body weight over the first $24 \mathrm{~h}$ of life, neither mucosal mass, DNA content, nor protein content of the artificially fed animals was different from that of newborn animals. In contrast, mucosal mass of the suckled animals was $75 \%$ greater, DNA content was $56 \%$ greater, and protein content was $93 \%$ greater than that of newborn animals. The mucosal protein/DNA ratio of the suckled animals was greater than that of newborn, but not artifically fed animals. The greater DNA, protein, and protein/DNA ratio in this group suggest that the greater mucosal mass is a result of both cellular hyperplasia and hypertrophy. Sucrase specific activity of the suckled animals was less than that of the artificially fed but not the newborn animals. Other disaccharidase activities were not different among the three groups.

These data extend the findings of Widdowson $e t$ al. (25) to another species and demonstrate that this rapid enteric growth over the first day of life results only from natural feeding. They strongly suggest, therefore, that rapid early enteric growth, mediated perhaps by a factor in natural milk that stimulates enteric mucosal growth, is an important heretofore unappreciated phase of intestinal development.

In contrast to the well described alterations that take place immediately after birth in many organ systems (i.e., the cardiovascular and respiratory symptoms), very little is known about 
the changes, if any, that occur in the gastrointestinal tract at birth when it assumes sole responsibility for the newborn's nutritional needs. One of the few studies concerning the changes in this organ immediately after birth is that of Widdowson et al. (25). In that study the enteric mucosa of normally suckled piglets increased markedly in mass during the first $24 \mathrm{~h}$ of life but did not change in piglets given only water during this period. Based on current concepts concerning regulation of mature enteric mucosa, the difference in response between these two groups of animals can be explained by the fact that the suckled animals in which growth occurred were fed whereas those animals in which no growth occurred were starved (22). Alternatively, growth could be due to the secondary release by feeding, but not by water, of one or more of the gastrointestinal hormones and/or secretions that have been implicated as regulatory factors in growth of intestinal mucosa $(1,2,13,15,20,24)$. On the other hand, the fact that the animals in which the marked mucosal growth was observed were suckled, not merely fed, raises the further unexplored possibility that natural feeding may be important in the control of enteric mucosal mass during early life. This possibility is suggested also by studies demonstrating that the natural milk of several animal species, including humans, contains one or more factors which stimulate growth of various types of cells in vitro $(6,18)$.

This study was undertaken to determine if the intestinal mucosa of the beagle puppy, like that of the pig, undergoes similar growth over the first $24 \mathrm{~h}$ of life and whether this growth occurs with artificial feeding as well as with natural feeding (i.e., suckling). In addition, the nature (i.e., hyperplasia versus hypertrophy) of enteric mucosal growth during the first $24 \mathrm{~h}$ of life was determined.

\section{MATERIALS AND METHODS}

Animals and tissue preparation. Pregnant beagles less than 5yr-old (Marshall Research Animals, Inc., North Rose, NY) were delivered to the animal care facilities of Columbia University College of Physicians and Surgeons at least 2 wk before the expected date of delivery. On arrival, they were placed in separate cages equipped with a whelping box and allowed free access to both a standard high protein ration and water. At delivery, newborn animals were separated from the mother, weighed, and kept warm until the entire litter (six to eight puppies) was born. Animals weighing more or less than 1 standard deviation from the mean weight of the litter were excluded from further studies; however, they were allowed to remain with the mother if necessary to maintain a litter size of four to six puppies. Animals meeting the weight criteria were assigned randomly either to be studied immediately $(n=5)$, returned to the mother and allowed to suckle normally for $24 \mathrm{~h}(n=5)$, or removed to a temperaturecontrolled room $\left(27-30^{\circ} \mathrm{C}\right)$ and fed artificially for $24 \mathrm{~h}(n=5)$. No more than two puppies per litter were assigned to a group. Usually, in fact, only one puppy per litter was assigned to each group.

Animals selected for study after $24 \mathrm{~h}$ of normal suckling remained with the mother in litters of four to six animals and were allowed to suckle ad libitum. Animals selected for study after $24 \mathrm{~h}$ of artificial feeding were fed every $2 \mathrm{~h}$ by nipple with sterilized formula (Esbilac, Borden Co., Columbus, OH) in amounts calculated to provide an energy intake of 180-200 kcal/ $(\mathrm{kg} \cdot \mathrm{d})$ and a protein intake of $12-13 \mathrm{~g} /(\mathrm{kg} \cdot \mathrm{d})$.

At the time of study (immediately after birth or $24 \mathrm{~h}$ of the assigned feeding regimen), animals were weighed and then decapitated. The small intestine from the ligament of Treitz to the caecum was removed as quickly as possible and its length measured using a tractional weight of $10 \mathrm{~g}$. This portion of the intestine was divided into five segments of equal length. Each segment was placed over ice, opened longitudinally, sponged with gauze to remove intestinal contents and scraped with a glass slide, always by the same investigator, to separate mucosal and nonmucosal tissue. These tissues, in turn, were placed in separate tared containers and weighed. The mucosal portion was frozen immediately in a dry ice/acetone mixture and then stored at $-70^{\circ} \mathrm{C}$. Other portions of the gastrointestinal tract (esophagus, stomach, duodenum, colon) were removed, opened longitudinally, sponged with gauze to remove their contents and weighed in toto. The liver and kidneys also were removed and weighed after sponging and dissection of adherent fat and connective tissue.

Chemical methods. Protein and DNA content as well as disaccharidase activities of the mucosal portion of the first, third, and fifth intestinal segments (proximal jejunem, mid-intestine, and distal ileum, respectively) were determined. For these analyses, the frozen mucosa of each segment was homogenized in cold $0.9 \% \mathrm{NaCl}$ using a glass-teflon homogenizer and the resulting homogenate was separated into appropriate aliquots for each assay. Total protein was determined by the method of Lowry et al. (21), DNA content by the method of Fleck and Munro (11), and disaccharidase activities by the method of Dahlqvist (9), with the glucose released being measured with glucostat reagent (Worthington Diagnostics, Freehold, NJ).

Statistical analysis. Statistically significant differences in any variable among the feeding groups were detected by analysis of variance. If a statistically significant difference was detected by this analysis, Student's or Dunnet's $t$ test was used to detect the group in which the variable was different.

\section{RESULTS}

As shown in Table 1, neither body weight, weight gain, nor the weight of non-intestinal organs of the suckled and artificially fed groups of animals was different either from each other or from that of newborn animals. In contrast, the weight of the stomach and duodenum of the suckled animals was greater than that of newborn animals, and the weight of the remaining small intestine (i.e., from the ligament of Treitz to the caecum) of these animals was greater than that of either newborn animals or animals that were fed artificially for the same period. The greater small intestinal mass of these animals was due entirely to a greater mucosal mass; neither length nor weight of the nonmucosal portion was different from that of either newborn or artificially fed animals. As shown in Figure 1, the greater mucosal mass was apparent in all except the most distal $20 \%$ of the small intestine (i.e., the terminal ileum). Mucosal mass of this segment was not different from that of either newborn or artificially fed animals.

Mucosal DNA and protein content mirrored mucosal weight (Table 2). Both were greater in suckled animals than in either

Table 1. Body and organ weights (g) of newborn puppies and puppies suckled normally or fed artificially for the first $24 \mathrm{~h}$ of life (mean $\pm S D)$

\begin{tabular}{lccc}
\hline & & & Fed artificially \\
& Newborn & Suckled $24 \mathrm{~h}$ & $24 \mathrm{~h}$ \\
\hline Body & $250.2 \pm 19.5$ & $286.8 \pm 22.9$ & $272.0 \pm 15.8$ \\
Esophagus & $0.34 \pm 0.07$ & $0.43 \pm 0.02$ & $0.40 \pm 0.06$ \\
Stomach & $1.17 \pm 0.18$ & $1.57 \pm 0.15^{*}$ & $1.39 \pm 0.19$ \\
Duodenum & $0.89 \pm 0.17$ & $1.27 \pm 0.09 \dagger$ & $1.11 \pm 0.02$ \\
Jejunum and ileum & $6.86 \pm 1.39$ & $10.02 \pm 1.20 \ddagger$ & $7.67 \pm 0.16$ \\
$\quad$ Mucosa & $3.35 \pm 0.73$ & $5.86 \pm 0.86 \S$ & $3.40 \pm 0.24$ \\
$\quad$ Non-mucosa & $3.50 \pm 0.70$ & $4.16 \pm 0.82$ & $4.27 \pm 0.24$ \\
Colon & $0.58 \pm 0.07$ & $0.77 \pm 0.12$ & $0.72 \pm 0.05$ \\
Liver & $14.4 \pm 1.3$ & $13.6 \pm 1.3$ & $13.6 \pm 0.4$ \\
Kidney & $3.37 \pm 0.53$ & $4.39 \pm 1.03$ & $3.90 \pm 0.28$ \\
\hline
\end{tabular}

* Significantly different from newborn $(P<0.05)$.

$\dagger$ Significantly different from newborn $(P<0.01)$.

$\ddagger$ Significantly different from both newborn $(P<0.01)$ and artificially fed $(P<0.05)$.

$\S$ Significantly different from both newborn $(P<0.01)$ and fed artificially $(P<0.01)$. 


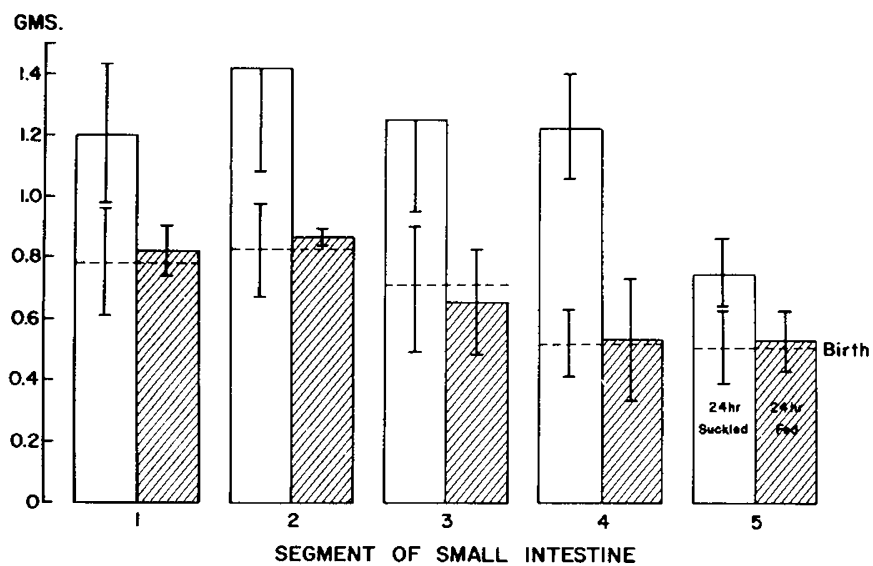

Fig. 1. Enteric mucosal mass (mean $\pm \mathrm{SD}$ ) of various segments (segment 1 is proximal $20 \%$ or proximal jejunum, segment 5 is distal $20 \%$ or distal ileum, etc.) of small intestine of suckled (open bars) and artificially fed (hatched bars) beagle puppies at $24 \mathrm{~h}$ of age. Mass of various segments of animals studied at birth are shown by horizontal broken lines.

newborn or artificially-fed animals. Despite the greater mucosal mass of the suckled animals, disaccharidase activities did not differ markedly among the three groups (Table 3 ). The only statistically significant difference in enzyme activity was a lesser sucrase specific activity in suckled compared with artificially fed animals. Although not statistically significant, lactase and maltase specific activities also tended to be less in this group. Despite possibly lower specific activities, total activity of all disaccharidases, because of the greater mucosal protein content, was greater in the suckled animals.

\section{DISCUSSION}

The data reported here indicate that only natural feeding during the first $24 \mathrm{~h}$ of life results in a dramatic increment in weight as well as protein and DNA content of the small intestinal mucosa of the beagle puppy. The greater DNA content indicates that the mucosal growth is the result of epithelial cell hyperplasia; however, the protein/DNA ratio of some segments is also greater indicating an element of hypertrophy as well.

This marked growth of enteric mucosa over the first day of life may represent a phase of intestinal development that has not been appreciated fully. Although numerous studies in a variety of animal species have delineated changes in enteric mucosal mass, turnover, and enzyme activities from the first 7-10 d of life to weaning (19), the changes that occur immediately after birth have received little attention. The data reported here on beagle puppies therefore, along with those of Widdowson et al. (25) on piglets and Berseth et al. (5) on rats, challenge the prevailing concept that enteric mucosal development is relatively quiescent during the entire neonatal period. Rather, in these three species there appears to be an early period of rapid growth. Presumably, this is followed by a relatively quiescent period and then by marked changes at the time of weaning. Further, in contrast to the seemingly pre-programmed and diet-independent changes that occur at the time of weaning, these early changes in the beagle occur only in naturally fed animals. No growth of enteric mucosa was observed in artificially fed animals.

The possibility that this dramatic difference in mucosal growth between naturally fed and artificially fed animals results from differences in intake and/or method of feeding cannot be excluded with certainty; however, this is unlikely. First, although weight gain during this period was minimal, neither weight gain nor body weight of the suckled and artificially fed groups was different. Second, we demonstrated that the intake of artificial formula provided [200 $\mathrm{kcal} /(\mathrm{kg} \cdot \mathrm{d})]$ produces growth equal to that of suckled puppies (14). Third, despite marked variations in
Table 2. Sum of mucosal DNA and protein contents $(m g)$ and protein/DNA ratio (mean $\pm S D$ ) of first, third, and fifth $20 \%$ of

jejunum + ileum of newborn puppies and puppies suckled normally or fed artificially for the first $24 \mathrm{~h}$ of life

\begin{tabular}{lccc} 
& & & Fed artificially \\
& Newborn & Suckled $24 \mathrm{~h}$ & $24 \mathrm{~h}$ \\
\hline DNA & $7.67 \pm 1.36$ & $11.99 \pm 1.71^{*}$ & $7.60 \pm 0.46$ \\
Protein & $131.5 \pm 28.0$ & $253.7 \pm 20.0^{*}$ & $136.3 \pm 7.7$ \\
Protein/DNA $\dagger$ & $17.1 \pm 1.1$ & $21.4 \pm 2.3 \ddagger$ & $18.0 \pm 1.9$ \\
\hline
\end{tabular}

* Significantly different from both newborns $(P<0.01)$ and fed artificially $(P<0.01)$.

$\dagger$ Mean of the ratios for each animal.

$\ddagger$ Significantly different from newborns $(P<0.05)$.

Table 3. Sum of mucosal disaccharidase activities ( $\mu \mathrm{mol}$ glucose $\cdot \mathrm{min}^{-1} \cdot \mathrm{mg}$ protein ${ }^{-1}$ ) of first, third, and fifth $20 \%$ of jejunum + ileum (mean \pm SD) of newborn puppies, and puppies suckled normally or fed artificially for the first $24 \mathrm{~h}$ of life

\begin{tabular}{lccc}
\hline & & & Fed artificially \\
& Newborn & Suckled $24 \mathrm{~h}$ & $24 \mathrm{~h}$ \\
\hline Lactase & $140 \pm 30$ & $90 \pm 10$ & $110 \pm 40$ \\
Sucrase & $15 \pm 3$ & $13 \pm 2^{*}$ & $20 \pm 4$ \\
Maltase & $75 \pm 9$ & $67 \pm 10$ & $74 \pm 17$ \\
\hline
\end{tabular}

* Significantly different from fed artificially $(P<0.05)$.

both overall growth and enteric mucosal growth, there was no correlation between total weight gain and mucosal weight. Because little is known about the micronutrient composition of canine colostrum, it is possible that the intakes of some nutrient(s) were different. In addition, differential effects of the method of feeding (i.e., suckling versus artificial feeding) cannot be excluded (26).

Despite these uncertainties, it seems more likely that the differences between naturally fed and artificially fed animals are related directly to one of the trophic factors known to be present in colostrum and/or milk $(6,18)$. One possibility is epidermal growth factor, which has been found in the milk of every species examined. This peptide stimulates proliferation of several cell and organ culture systems in vitro, including gastrointestinal epithelium $(3,7,8)$. It also increases ornithine decarboxylase activity (an index of protein synthesis) of intestinal mucosa in vivo (10). Another possibility is taurine which, as demonstrated recently by Gaull et al. (12), is mitogenic for cultured lymphocytes. Because the taurine concentration of canine milk is relatively high and the artificial formula contains virtually none, it is likely that the intraluminal taurine concentration of naturally fed animals is higher than that of artificially fed animals. It remains to be proven whether or not this probable difference in intraluminal taurine concentration or the presence in natural milk of specific trophic factors accounts for the greater mucosal growth of the naturally fed animals.

Many other factors, both hormonal and non-hormonal, are known to influence enteric mucosal mass and enzyme activities of newborn as well as adult animals. Of the hormonal factors, gastrin has been the most extensively studied $(16,17)$. Berseth et al. (4), in fact, observed higher serum levels of gastrin in beagle puppies suckled normally for $2 \mathrm{~d}$ than in puppies fed artificially. Although natural milks are not known to contain gastrin and although there is no reason to expect that natural feeding results in greater serum gastrin levels than artificial feeding, the higher serum gastrin concentration and the greater enteric mucosal mass of suckled animals suggest a cause-and-effect relationship. Nonetheless, the importance of gastrin in early intestinal development remains to be determined.

A number of non-gastrointestinal hormones known to be present in natural milks (i.e., thyroxin, corticosteroids) enhance maturation of enteric mucosa (23), but the enteric mucosal 
growth observed in the suckled animals was not accompanied by maturational changes (i.e., changes in the specific activity of mucosal disaccharidases). It is unlikely that the greater mucosal growth of suckled animals was mediated by one of these agents.

Pancreatic and biliary secretions are examples of non-hormonal factors which exert trophic effects on intestinal mucosa $(1,2)$. For example, diversion of the contents of the intestinal lumen of rats decreases the proliferative enteric cell pool, reduces enteric cell shedding, and markedly decreases labeling index. The fact that these changes are reversed by duodenal perfusion with sodium taurocholate (24) suggests that bile acids may exert a particularly important influence on enterocyte kinetics. With respect to the mechanism of the enteric growth reported here, however, there is no evidence that natural milk stimulates biliary secretions to a greater extent than artificial formula.

In conclusion, the data reported here show that the enteric mucosa of naturally fed but not artificially fed beagle puppies undergoes marked growth over the first $24 \mathrm{~h}$ of life. It seems likely that some factor (or factors) present only in natural milk is responsible for this marked growth. Although the precise mechanism remains to be determined, this effect on the intestine during the immediate neonatal period undoubtedly plays an important role in adaptation of the newborn beagle puppy to extrauterine life. Similar effects of natural feeding on other species [i.e., the rat (5) and the pig (25)] suggest that natural feeding may be important in adaptation of all species to extrauterine life.

\section{REFERENCES AND NOTES}

1. Altman, G. G.: Influence of bile and pancreatic secretion on the size of intestinal villi in the rat. Am. J. Anat., 132: 167 (1971).

2. Altman, G. G. and Leblond, C. P.: Factors influencing villus size in the small intestine of adult rats as revealed by transposition of intestinal segments. Am. J. Anat., 127: 15 (1970).

3. Beaulieu, J-F. and Calvert, R.: The effect of epidermal growth factor (EGF) on the differentiation of the rough endoplasmic reticulum in fetal mouse small intestine in organ culture. J. Histochem. Cytochem., 29: 765 (1981).

4. Berseth, C. L., Lichtenberger, L. M., Bayley, H. S., and Morriss, F. H.: Role of endogenous gastrin in mediating colostrum-stimulated gut growth. Pediatr. Res. (abstract), 16: 156A (1982).

5. Berseth, C. L., Lichtenberger, L. M., and Morriss, F. H., Jr.: Comparison of the gastrointestinal growth-promoting effects of rat colostrum and mature milk in newborn rats in vivo. Am. J. Clin. Nutr., 37: 52 (1983).

6. Carpenter, G.: Epidermal growth factor is a major growth promoting agent in human milk. Science, 210: 198 (1980).

7. Cohen, S.: Isolation of a mouse submaxillary gland protein accelerating incisor eruption and eyelid opening in the newborn animal. J. Biol. Chem., 237: 1555 (1962).
8. Cohen, S. and Taylor, J. M.: Epidermal growth factor: chemical and biological characterization. Recent Prog. Horm. Res., 30: 533 (1974).

9. Dahlqvist, A.: Assay of intestinal disaccharidases. Anal. Biochem., 22: 99 (1968).

10. Feldman, E. J., Aures, D., and Grossman, M. I.: Epidermal growth factor stimulates ornithine decarboxylase activity in the digestive tract of mouse. Proc. Soc. Exp. Biol. Med., 159: 400 (1978).

11. Fleck, A. and Munro, H. N.: The precision of ultraviolet absorption measurements in the Schmidt-Thannhauser procedure for nucleic acid estimation. Biochem. Biophys. Acta, 55: 571 (1962).

12. Gaull, G. E., Wright, C. E., Schweitzer, L. B., and Tallan, H. H.: Taurine enhances the proliferation of cultured human cells. Clin. Res. (abstract), 30: $621 \mathrm{~A}(1982)$.

13. Gleeson, M. H., Bloom, S. R., Polak, J. M., Henry, K., and Dowling, R. M.: An endocrine turnover in kidney affecting small bowel structure, motility and absorptive function. Gut, 12: 773 (1971).

14. Heird, W. C. and Brasel, J. A.: Unpublished data.

15. Johnson, L. R. and Guthrie, P.: Effect of cholecystokinin and 16,16-dimethyl prostaglandin $\mathrm{E}_{2}$ on RNA and DNA of gastric and duodenal mucosa. Gastroenterology, 70:59 (1976).

16. Johnson, L. R., Guthrie, P. D., and Dudrick, S. J.: Effects of luminal gastrin on the growth of rat intestinal mucosa. Gastroenterology, 81: 71 (1981).

17. Johnson, L. R., Lichtenberger, L. M., Copeland, E. M., Dudrick, S. J., and Gilbert, A.: Action of gastrin on gastrointestinal structure and function. Gastroenterology, 68: 1184 (1975).

18. Klagsbrun, M.: Human milk stimulates DNA synthesis cellular proliferation in cultured fibroblasts. Proc. Natl. Acad. Sci., U. S. A. 75: 5057 (1978).

19. Klein, R. M. and McKenzie, J. C.: The role of cell renewal in the ontogeny of the intestine. I. Cell proliferation patterns in adult, fetal and neonatal intestine. J. Pediatr. Gastroenterol. Nutr., 2:10 (1983).

20. Lichtenberger, L. M. and Johnson, L. R.: A role of gastrin in the ontogenic development of the small intestine. Am. J. Physiol., 227: 390 (1974).

21. Lowry, O. H., Rosenbrough, N. J., Farr, A. L., and Randall, R. J.: Protein measurement with the folin phenol reagent. J. Biol. Chem., 193: 265 (1951).

22. McNeill, L. K. and Hamilton, J. R.: The effect of fasting on disaccharidase activity in the rat small intestine. Pediatrics, 47: 65 (1971).

23. Moog, F.: Perinatal development of the enzymes of the brush-border membrane. In: Emanuel Lebenthal: Textbook of Gastroenterology and Nutrition in Infancy. pp. 137-147 (Raven Press, New York, 1981).

24. Roy, C. C., Laurendeau, G., Doyon, G., Chartrand, L., and Rivest, M. R.: The effect of bile and of sodium taurocholate on the epithelial cell dynamics of the rat small intestine. Proc. Soc. Exp. Biol. Med., 149: 1000 (1975).

25. Widdowson, E. M., Columbo, V. E., and Artavanis, C. A.: Changes in the organs of pigs in response to feeding for the first $24 \mathrm{~h}$ after birth. II. The digestive tract. Biol. Neonate, 28: 272 (1976)

26. Young, E. A., Cioletti, L. A., Traylor, J. B., and Balderas, V.: Gastrointestinal response to oral versus gastric feeding of defined formula diets. Am. J. Clin. Nutr., 35: 715 (1982)

27. Requests for reprints should be addressed to: Dr. William C. Heird, Associate Professor of Pediatrics, Columbia University College of Physicians \& Surgeons, 630 West 168th Street, New York, New York 10032.

28. This research was supported by grants $H D-08432$ and $H D-13284$ from the National Institutes of Health.

29. Received for publication January 31,1983

30. Accepted for publication August 17, 1983.

\title{
9th European Congress of Perinatal Medicine
}

\author{
SEPTEMBer 3-5, 1984 \\ Royal Dublin Society, Dublin, Ireland
}

Topics include antenatal fetal assessment, monitoring the baby during labor, asphyxial brain damage, and the contribution of perinatal physiology to clinical practice. The program is designed to highlight areas of current controversy and debate.

In addition, the Congress will feature an exhibition in which conferees can see first hand how rapid technologic changes have affected their specialty.

For further information and travel arrangements, call the Congress' official agent, Kenness International at 800-235-6400 [in New York, call (212) 684-2010]. 